\title{
Application Practice of Interactive Teaching Method in College Vocal Music Teaching
}

\author{
Dou Lianxiu \\ Dongchang College, Liaocheng University, Shandong, China, 252000
}

Keywords: college vocal music teaching; interactive teaching; application

Abstract: Vocal music teaching is an important teaching category in China's higher education system. It plays an important role in cultivating the music quality of college students and promoting the development of education quality in China. However, as far as the present situation is concerned, the teaching effect of college vocal music teaching is not ideal, and the old teaching methods can't adapt to the changing teaching practice. In this context, interactive teaching is highly valued. In college vocal music teaching, the use of interactive teaching method is not only conducive to improving students' subjective consciousness, but also conducive to effective communication between teachers and students. This paper analyzes the present situation of college vocal music teaching in China, and discusses the significance of the application of interactive teaching in college vocal music teaching, as well as the application way of interactive teaching in college vocal music teaching.

\section{Introduction}

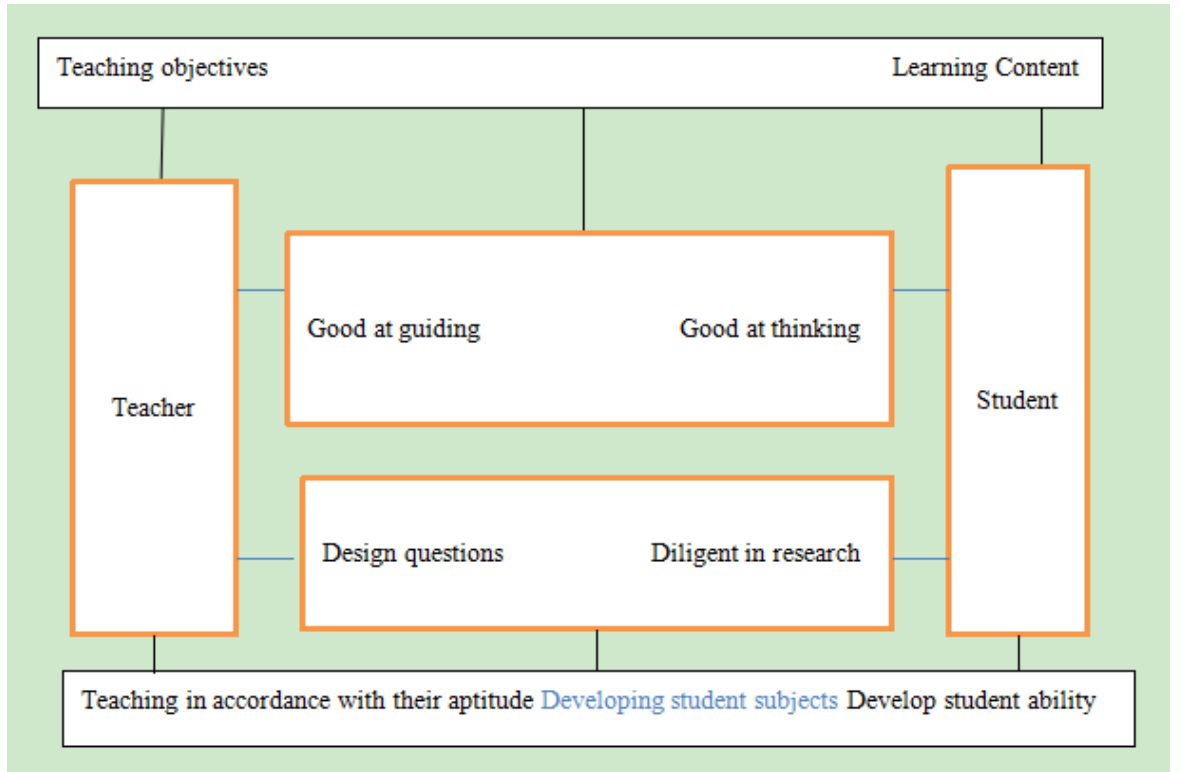

Figure 1 Interactive classroom teaching mode 
With the continuous deepening of the higher education system, teaching methods and teaching methods are constantly updated. In the teaching of vocal music education in universities, the application of interactive teaching methods is also increasingly widespread. Figure 1 is an interactive classroom teaching mode diagram, the interactive teaching method can take students as the main body and create a good curriculum teaching atmosphere through mutual communication between teachers and students to promote students' self-help learning. Under the influence of the modern teaching environment, the whole teaching activities not only require the active guidance of the teachers, but also require the active participation of the students to achieve the teaching purpose of teaching and learning. Therefore, in the vocal music teaching activities, interactive teaching is a good attempt, which plays an important role in exploring students' independent innovation ability and cultivating students' subjective initiative ${ }^{[1]}$.

\section{The current situation of college vocal music teaching}

In recent years, with the continuous deepening of education and teaching reform, the teaching concept has been continuously updated. Under the impetus of curriculum teaching reform, the teaching methods of vocal music teaching in colleges and universities have changed. However, influenced by the traditional educational teaching philosophy, vocal music teaching still has the following aspects:

First, the teaching objectives are not clear enough, and the teaching methods have not yet got rid of the traditional teaching mode. College students are more active in their ideology, and they pay more attention to self-consciousness in the process of learning. If the teaching lacks innovation and always teaches step by step, it is not only difficult to stimulate students' interest. Over time, it is easy to make students feel tired of learning.

Second, teachers lead the classroom, and classroom teaching is based on the demonstration teaching method. In the university vocal music teaching, although the traditional teaching methods have also played some effects, the role is limited. The teacher-led classroom teaching mode seriously affects the students' subjective consciousness. The teachers do the demonstration exercises while doing guidance, adopting the demonstration teaching method, and the single teaching atmosphere is limited, which limits the students' initiative.

Third, it is necessary to further improve the professional quality and professional comprehensive ability of teachers. Teachers play an important role in teaching. The student's learning process is determined by the professional level of the teacher, and the teacher's patience and sense of responsibility will have a direct impact on the student's learning outcome. However, the current teaching capacity of some schools is still relatively weak, and the comprehensive professional ability of teachers is not very strong, which will cause many obstacles for students' vocal music learning. Over time, they will become bored and even contradict the study of vocal music, thus reducing the overall teaching quality ${ }^{[2]}$.

\section{The significance of using interactive teaching methods in college vocal music teaching}

The interactive teaching method is a new teaching method, which creates a free, democratic and harmonious classroom atmosphere by strengthening the effective interaction between teachers and students. Under this kind of classroom teaching atmosphere, students can treat learning with a relaxed and happy attitude, thus improving learning efficiency. In the teaching of vocal music in colleges, the application of interactive teaching methods has important significance. 


\subsection{Improve teachers' teaching skills}

The essence of the interactive teaching method is " interaction", which requires teachers to strengthen classroom communication and communication. In the traditional vocal music teaching mode, the interaction between teachers and students is very small. In most cases, the teachers implement the teaching steps according to the proposed teaching plan, and everything is carried out step by step. In this case, the implementation of interactive teaching method is a challenge for teachers. Teachers need to have a new understanding of interactive teaching methods, but also need to master certain communication skills and the ability to control the classroom rhythm. Therefore, after implementing the interactive teaching method, teachers can effectively improve teaching skills and enrich teaching experience.

\subsection{Highlight the subjective status of students}

The subjective status of students' teaching is an objective requirement of the current education system, which is always ignored in the traditional teaching mode. After the implementation of the interactive teaching method, the teaching reflects the relationship between teaching and learning, that is, the teacher and the students jointly create the classroom, and the students can fully take the initiative. This teaching method just saves students from passive learning, and the teaching burden of teachers can be reduced ${ }^{[3]}$.

\subsection{Stimulate students' ability to innovate}

In the traditional vocal music teaching mode, teachers always bias the teaching focus to music theory, and the most commonly used teaching method is the explanation method. Under the influence of this teaching mode, it is difficult for students to produce enthusiasm for learning, and it is also difficult to have creative thinking. In the long run, the students' music level and musical ability will decline. After the implementation of the interactive teaching method, teachers will give students more opportunities to speak in the classroom, so that students can fully express their views. In this relatively free learning atmosphere, students' abstract thinking and understanding skills will be greatly improved, and the creativity of learning will be enhanced. Table 1 shows the results of the relevant survey results for students after applying the interactive teaching method.

Table 1 Interactive teaching student questionnaire results

\begin{tabular}{cccc}
\hline Aspect & Grade & Number of people & Proportion \\
\hline \multirow{3}{*}{ Teaching effect } & good & 138 & $86.8 \%$ \\
& general & 19 & $11.9 \%$ \\
& bad & 2 & $1.3 \%$ \\
Schedule & long & 7 & $4.4 \%$ \\
& suitable & 135 & $84.9 \%$ \\
Interactive project & short & 17 & $10.7 \%$ \\
& increase & 37 & $23.3 \%$ \\
& suitable & 110 & $69.2 \%$ \\
Vocal teaching satisfaction & decrease & 12 & $7.5 \%$ \\
& satisfaction & 140 & $88.1 \%$ \\
& ordinary & 13 & $8.2 \%$ \\
& dissatisfaction & 6 & $3.8 \%$ \\
\hline
\end{tabular}




\section{The application of interactive teaching method in college vocal music teaching}

The application of interactive teaching method in university vocal music teaching should mainly start from the following points:

\subsection{Correct understanding of ideas}

To apply the interactive teaching method, we should first correctly understand its connotation and concept, and apply it to the specific teaching on the basis of fully grasping the essence of the concept. Interactive teaching can be interpreted literally as "communicative teaching", but if it is applied to vocal teaching, it is far more than simple. It not only requires efficient communication between teachers and students, but also objectively requires the pertinence of communication. In interactive teaching, the ultimate goal of communication and interaction is to guide students to concentrate on the learning state, fully stimulate students' self-directed learning consciousness, and mobilize students' learning enthusiasm from within. Therefore, in vocal music teaching, teachers should effectively combine the basic concepts of interactive teaching with teaching tasks when teaching design, and strive to give full play to the positive role of interactive teaching ${ }^{[4]}$.

\subsection{Create a relaxed atmosphere}

In addition to the correct grasp of the concept, the application of interactive teaching methods in vocal music teaching should also focus on creating a good and relaxed atmosphere. In the vocal music teaching, in addition to the theoretical teaching link, the actual training needs to practice the vocalization. The sound effect is not only related to the students' own state, but also has a great relationship with the teaching atmosphere. The application of interactive teaching methods should start from the specific feelings of students, create a good and relaxed learning environment, slow down the psychological pressure of students, create conditions for students to achieve effective learning and independent learning, and lay the foundation for the exchange between teachers and students.

\subsection{Rational use of the import link}

In addition to the reasonable creation of the teaching atmosphere, the application of interactive teaching methods in the teaching of vocal music in universities should also make rational use of the importing links. The introduction process is the initial stage of the course teaching, and it is also a part of the decision-making effect on the teaching effect of the class. The interactive teaching process requires the close cooperation of teachers and students, but if the students are lazy or free at the beginning of the course, it is almost impossible for the teacher to turn around in the next teaching. In view of this situation, teachers are advised to make full use of the multimedia teaching mode in the import process, to attract students' attention through situation creation or appreciation of works, to concentrate students' attention and lay a solid foundation for the next teaching ${ }^{[5]}$.

\section{Conclusions}

In conclusion, the implementation of interactive teaching method in college vocal music teaching is conducive to enriching teaching methods and improving teaching effects. This teaching method can stimulate students' interest in learning, arouse their enthusiasm and initiative, enhance their sense of competition, and train and improve their creative thinking, logical thinking and language expression ability in the process of interaction with students. Therefore, on the way of teaching in 
the future, interactive teaching method should be further promoted and improved to enhance the effectiveness of classroom teaching and promote the all-round development of students.

\section{References}

[1] Liu Li. Exploring the Application of Interactive Teaching Methods in College Vocal Music Teaching[J]. Journal of Public Art, 2014(16): 68-68.

[2] Hu Aihua. The Application of Interactive Teaching Method in College Vocal Music Teaching[J]. Musical Concept, 2012(6):200-202.

[3] Guo Jinrui. Application of Interactive Teaching Method in College Vocal Music Teaching[J]. Art Science, 2015(5): 258-258.

[4] Zhang Di. Exploring the Application of Interactive Teaching Methods in College Vocal Teaching[J]. Theatre House, 2014(12): 68-68.

[5] Chen Wei. Research on the Application of Interactive Teaching Method in College Vocal Music Teaching[J]. Northern Music, 2014(7): 213-214. 